Issued by Sandia National Laboratories, operated for the United States Department of Energy by Sandia Corporation.

NOTICE: This report was prepared as an account of work sponsored by an agency of the United States Government. Neither the United States Government, nor any agency thereof, nor any of their employees, nor any of their contractors, subcontractors, or their employees, make any warranty, express or implied, or assume any legal liability or responsibility for the accuracy, completeness, or usefulness of any information, apparatus, product, or process disclosed, or represent that its use would not infringe privately owned rights. Reference herein to any specific commercial product, process, or service by trade name, trademark, manufacturer, or otherwise, does not necessarily constitute or imply its endorsement, recommendation, or favoring by the United States Government, any agency thereof, or any of their contractors or subcontractors. The views and opinions expressed herein do not necessarily state or reflect those of the United States Government, any agency thereof, or any of their contractors.

Printed in the United States of America. This report has been reproduced directly from the best available copy.

Available to DOE and DOE contractors from Office of Scientific and Technical Information

P.O. Box 62

Oak Ridge, TN 37831

Prices available from (703) 605-6000

Web site: http://www.ntis.gov/ordering.htm

Available to the public from

National Technical Information Service

U.S. Department of Commerce

5285 Port Royal Rd

Springfield, VA 22161

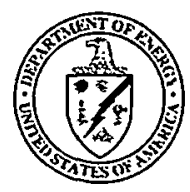




\section{DISCLAIMER}

Portions of this document may be illegible in electronic image products. Images are produced from the best available original document. 
SAND99-2982

Unlimited Release

Printed November 1999

\title{
Low Work Function Thermionic Emission Materials
}

\author{
Kevin R. Zavadil \\ Interface Reliability: \\ Adhesion, Cleaning, Corrosion, and Tribology \\ Donald B. King \\ International Nuclear Safety \\ Judith A. Ruffner \\ Electronic and Optical Materials \\ Sandia National Laboratories \\ P.O. Box 5800 \\ Albuquerque, NM 87185-0340
}

\begin{abstract}
Thermionic energy conversion in a microminiature format shows potential as a viable, high efficiency, "on-chip" power source. Microminiature thermionic converters (MTC) with inter-electrode spacings on the order of microns are currently being prototyped and evaluated at Sandia. The remaining enabling technology is the development of low work function materials and processes that can be integrated into these converters. In this report, we demonstrate a method of incorporating thin film emitters into converters using rf sputtering. We find that the resultant films possess a minimum work function of 1.2 $\mathrm{eV}$. Practical energy conversion is hindered by surface work function non-uniformity. We postulate the source of this heterogeneity to be a result of limited bulk and surface transport of barium. Several methods are proposed for maximizing transport, including increased film porosity and the use of metal terminating layers. We demonstrate a novel method for incorporating film porosity based on metal interlayer coalescence.
\end{abstract}




\section{Contents}

Introduction .................................................................. 3

Microminiature Thermionic Converter Concept .............................. 3

Emitter Film Design ........................................................... 4

Emitter Film Fabrication ...................................................... 5

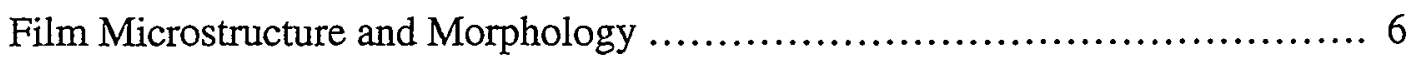

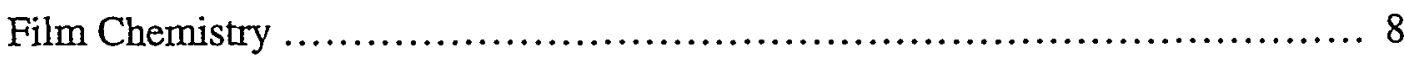

Film Surface Chemistry .................................................... 9

Emission Properties of Thin Film Emitters ................................... 11

Conclusions .............................................................. 16

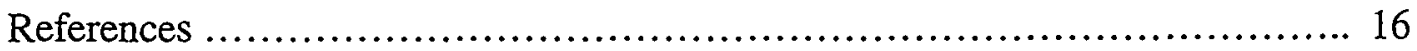




\section{Introduction}

A growing demand exists for local power sources that can be integrated into small scale devices and modules. Thermionic energy conversion shows promise as one method for generating local power, provided the efficiencies obtained for higher temperature diodes of 5 to $10 \%$ can be produced for lower temperature applications. High efficiency at low temperature requires the use of a low work function, highly electron emissive cathodes in small gap diodes where space charge fields cannot develop. Using such a cathode, calculations show that the efficiency of a microminiature thermionic converter (MTC) with an interelectrode gap of one to ten microns can exceed 20\%[1]. MTC's require a thin film emitter that can be integrated into the fabrication of the diode at a given thickness to yield a high tolerance gap distance. Highly emissive cathode materials have been developed by the electron source community based on barium oxide and scandia $\left(\mathrm{Sc}_{2} \mathrm{O}_{3}\right)$ [2]. However, these emitters are macroscopic structures derived by impregnating porous tungsten monoliths with barium $(\mathrm{Ba})$. Scandia is either incorporated into the original tungsten $(W)$ structure, as part of the impregnate or as a capping layer. Our goal is to develop methods for depositing highly emissive films within this class of materials that can be integrated into an MTC device.

\section{Microminiature Thermionic Converter Concept}

Figure 1 illustrates the components and processes of a typical thermionic converter. A heat source elevates the temperature of the emitter (typically, between $1500-2200 \mathrm{~K}$ ). Electrons are then thermally evaporated into the space (the interelectrode gap, IEG) between the emitter electrode and collector electrode. The electrodes are operated in a vacuum or low pressure vapor (less than several torr). The collector electrode is cooled by a heat sink and kept at a low temperature. The electrons travel across the IEG toward the collector electrode and condense on the collector. The electrons then return to the emitter through the electrical leads and load that connect the collector to the emitter. The thermionic conversion efficiency is given by the ratio of the electrical energy output to the total heat input.

We envision the fabrication of a planar microminiature thermionic diode. Conventional integrated circuit fabrication techniques would be used to produce single devices as well as arrays of devices. All elements of the diode (emitter, collector, and insulating spacer between the electrodes) are made with standard sputtering and/or chemical vapor deposition (CVD) techniques and etch techniques used by the semiconductor industry. Thin film deposition techniques allow us to reliably, reproducibly, and accurately grow extremely thin layers of metals (for the electrodes) and oxides (for the spacers). A conceptual fabrication process is illustrated in Figure 2. The emitter material is first deposited onto a suitable substrate material. Emitter materials with different work functions can be deposited to optimize emission temperature for each application. Next, an oxide layer is deposited over the emitter material. This layer ultimately serves as the spacer between the emitter and collector. The oxide layer can be varied from several thousand Angstroms to several microns to control the diode gap size. The collector material is deposited over the oxide spacer material. Collector materials with different work functions can also be deposited to optimize the output voltage at which emission occurs. Several holes are etched through the collector material to the oxide spacer using 


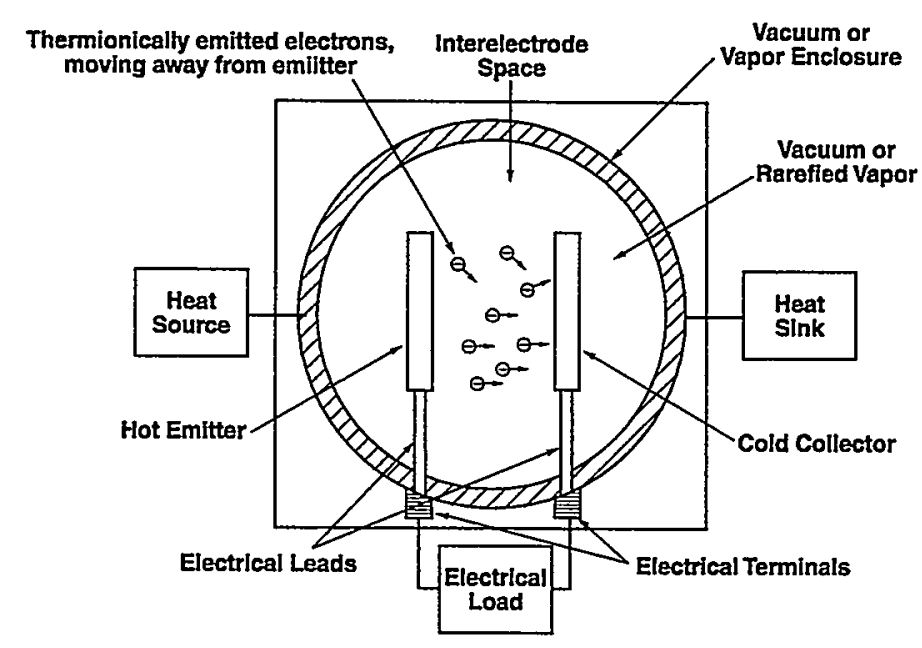

Figure 1. Thermionic Converter Elements and Processes.
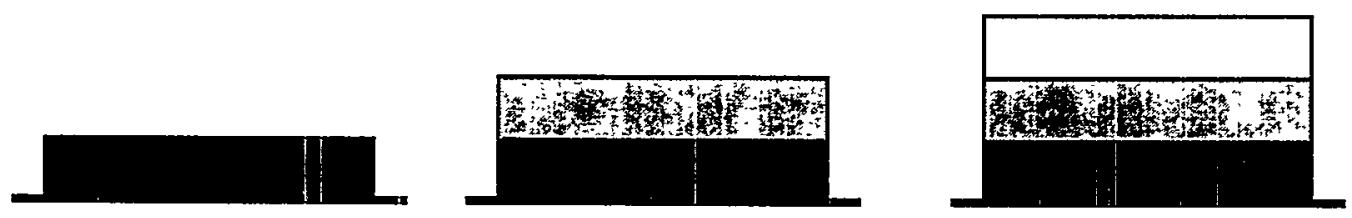

\section{Deposit emitter}

2. Deposit oxide spacer

3. Deposit collector
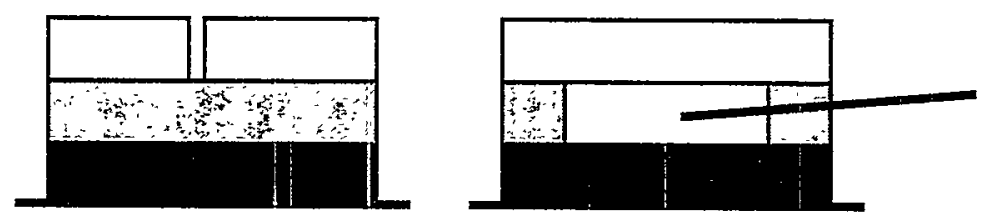

interelectrode gap

\section{Fabricate etch vias}

\section{Etch oxide spacer}

Figure 2: Conceptual illustration of the fabrication of a microminiature thermionic converter (MTC)

reactive ion etching (RIE). The internal oxide spacer material is etched away to form the vacuum space between the emitter and collector.

\section{Emitter Film Design}

Barium is the oxide material of choice in thermionic cathodes. Extensive work by the vacuum tube and electron gun communities established the role of $\mathrm{Ba}$ in macroscopic emitter structures [3]. $\mathrm{Ba}$ is viewed as an adsorbate that lowers the surface work function 
through the formation of a surface dipole. A life cycle for $\mathrm{Ba}$ exists that starts with localized reduction to produce free $\mathrm{Ba}$ from the host oxide, transport of free $\mathrm{Ba}$ through the bulk emitter, surface diffusion of $\mathrm{Ba}$ along the surface and eventual desorption and loss. The classic barium-strontium-calcium oxide $(\mathrm{BaSrCaO})$, used in the tube industry and formed from the carbonates, retains considerable carbon in the annealed matrix to act as the local reductant. These films contain intrinsic porosity and it is assumed that this porosity aids in $\mathrm{Ba}$ transport via local vapor transport. The electron source community has settled on porous $\mathrm{W}$ forms that are impregnated with a $\mathrm{BaCO}_{3}, \mathrm{CaCO}_{3}$ and $\mathrm{Al}_{2} \mathrm{O}_{3}$ mixture at elevated temperature in hydrogen or vacuum. The $\mathrm{W}$ structure acts as a support, an internal electron conductor and supplies large interfacial area for $\mathrm{Ba}$ reduction. This latter design cannot be used to produce thin films, although the concepts can be incorporated into a thin film structure.

Our strategy is to develop methods for producing emissive thin films within the Ba oxide materials class[4]. Two concepts for Ba-containing thin film emitters are schematically shown in Figure 3. The first film utilizes the deposition of a $\mathrm{Ba}$ oxide on an electrode substrate that will act as the local reductant. The oxide is a 47.5:47.5:5 mole fraction $\mathrm{BaSrCaO}(\mathrm{BSCO})$ sputter deposited onto a tantalum (Ta) electrode. In choosing $\mathrm{BSCO}$, our intent is to form a trioxide without the need for $\mathrm{CO}_{2} / \mathrm{CO}$ emission during activation. The Ta electrode will act as a local reduction region with the formation of tantalate phase. The film is actually a composition modulated structure with alternating layers of BSCO and Sc203. Scandia is known to improve emission properties for oxide cathodes[5]. Modulation also provides a method for limiting atmospheric moisture ingress into the film. Previous attempts at depositing bi-layer films of BSCO with a scandia capping layer showed that the BSCO deliquesces resulting in film instability [6]. Modulated films of BSCO and scandia can be stored in atmosphere and will retain their specular surface finish.

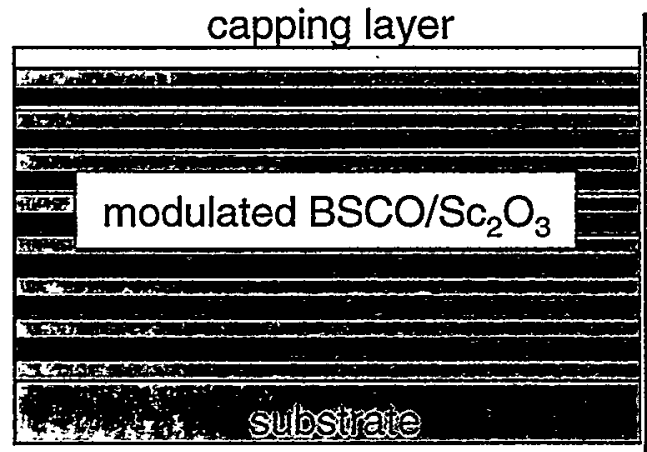

(a)

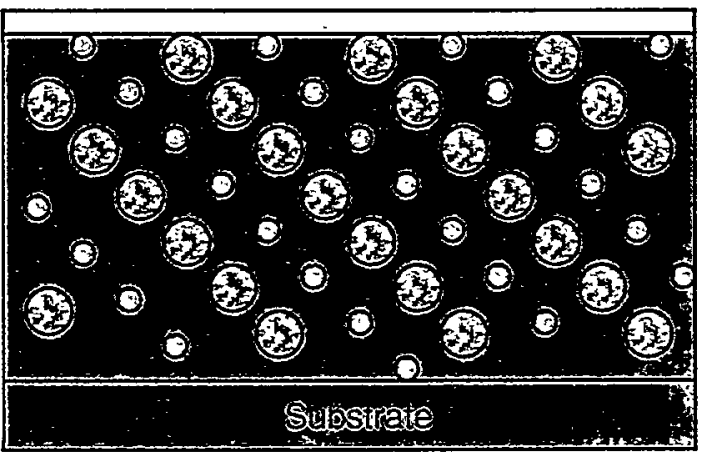

(b)

Figure 3: Deposition design strategies for thin film thermionic emitters: (a) a composition modulated structure made up of alternating layers of $\mathrm{BSCO}$ and $\mathrm{Sc}_{2} \mathrm{O}_{3}$, (b) phase-separated $\mathrm{W} / \mathrm{BaO}$ micro-dispenser thin film cathode. 
The second strategy involves fabricating a micro-dispenser cathode. This concept takes advantage of the modulated structure and the ability to incorporate a reductant throughout the film. Tungsten is included in the structure of the film. Annealing produces a coalescence of the $\mathrm{W}$ as discrete particles. The resulting structure possesses phaseseparated $\mathrm{W}$ and $\mathrm{Ba}$ oxide film where $\mathrm{W}$ particles mimic the electrical backbone present in the macro-dispenser cathodes generated by the electron source community. The use of barium calcium aluminate $\left(\mathrm{BaCaAlO}_{\mathrm{x}}, 4: 1: 1\right.$ mixed oxide in the target) eliminates the instability of the film toward moisture. The resulting films provide a stable support structure on which to deposit surface modifying layers tailored for emission properties.

\section{Emitter Film Fabrication}

Thin cathode films are deposited using rf sputtering. Deposition is conducted in a Unifilm PVD300 system with both substrate translation and rotation to ensure film thickness uniformity. Shadow masks are used to define electrode and cathode patterns on the substrate. Intrinsic silicon ( $\mathrm{Si}$ ) with a $400 \mathrm{~nm}$ thermal oxide, aluminum nitride or sapphire wafers are used as the substrates. Tantalum or platinum $(500 \mathrm{~nm})$ is used as the base electrode film with a thin $(30 \mathrm{~nm})$ titanium layer to ensure bonding integrity at elevated temperatures. The emitter is some composition of $\mathrm{BaSrCaO}$ or $\mathrm{BaCaAlO}_{\mathrm{x}}, \mathrm{Sc}_{2} \mathrm{O}_{3}$ and $\mathrm{W}$ depending on the desired film composition. The films are deposited sequentially in a modulated structure with relative thicknesses and periods dependent on desired properties.

Radio frequency (rf) sputtering is the deposition method of choice. The small gap sizes desired in a microminiature thermionic scheme require thin films with a thickness uniformity and surfaces with a roughness that is a small fraction of the actual gap size. A commercial sputtering system, like the PVD300 system used in this study, are capable of better than $98 \%$ thickness uniformity over 4 inch distances. A full conversion device will require a deposition scheme that can be integrated into a more complex fabrication process. The desired films are multi-component and sputtering is only limited by an ability to fabricate the respective materials into targets. Chemical vapor deposition (CVD) is certainly an alternate deposition method, but would require working out the chemistry for the mixed oxides.

Films are currently deposited using shadow mask methods. A schematic representation of this process is shown in Figure 4. Masks exist for the base electrode layer and emitter layers. More complex schemes have been used to incorporate thermocouples into the device structures or to provide emitter samples whose structure is amenable to high temperature resistivity measurements. Additional mask layers are inserted into the deposition sequence. Figure 4 shows an example of an emitter that is been deposited to date. The possibility exists for using lithographic masks and producing much smaller spatial features. We find that $\mathrm{BaCaAlO}_{\mathrm{x}}$ is stable toward acetone making lift-off processes, using standard photoresists, a possibility. Smaller features would allow for vertical structure to be built into these films. A very high surface area emitter could be fabricated by depositing $\mathrm{W}$ columns followed by a $\mathrm{BaCaAlO}_{\mathrm{x}}$ inflow to produce an alternate micro-dispenser cathode design. 

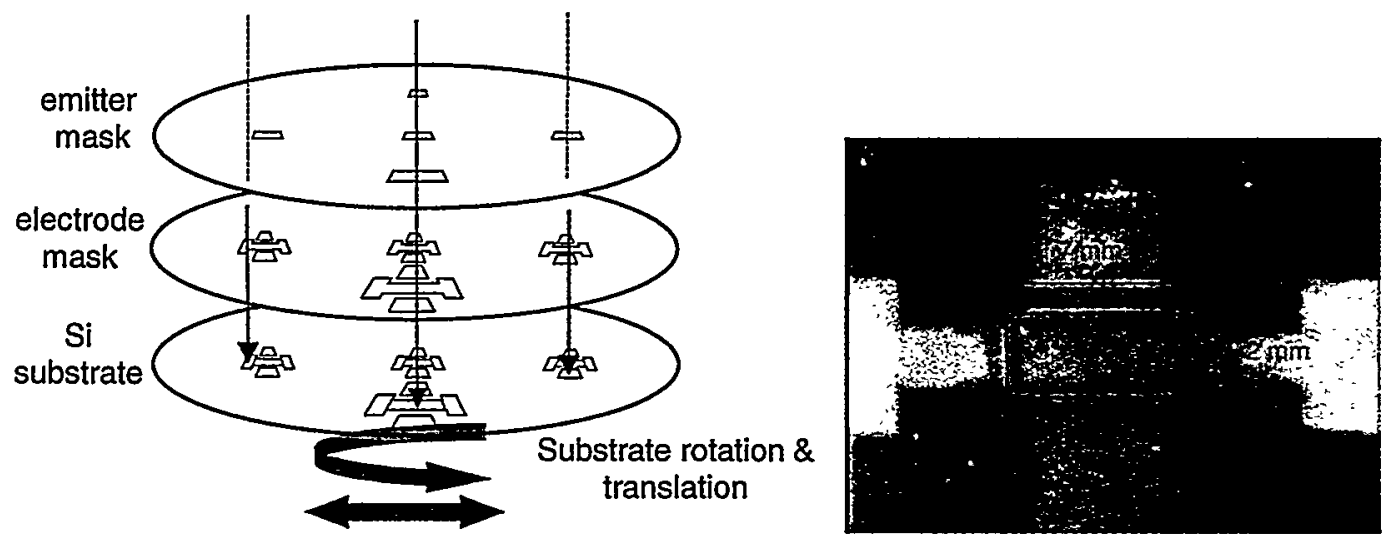

Figure 4: Deposition process for patterned thin film emitters and the resulting product

\section{Film Microstructure and Morphology}

Emitters are routinely deposited in a compositional modulated form. Modulation is a convenient way of incorporating multiple components into the film and preserving film structure when reactive constituents are present. The electron micrograph of Figure 5a shows a cross-sectional view of a modulated film annealed to $1300 \mathrm{~K}$. This specific film contains a series of 4 BSCO layers and 3 scandia layers each of $100 \mathrm{~nm}$ in thickness. The final capping film is a $400 \mathrm{~nm}$ scandia layer. The interfaces between each layer are visible at this fractured edge. Individual crystallite structure is difficult to determine at this length scale. We do not see evidence of columnar crystal growth for the $100 \mathrm{~nm}$ layers where it is clearly visible in the thicker $400 \mathrm{~nm}$ scandia capping layer. Thicker BSCO films also show a similar columnar structure. Plan view microscopy shows that the columnar deposits can have terminal grain sizes of approximately $50 \mathrm{~nm}$. Thinner layer microstructure is difficult to resolve and indicates smaller grain sizes. The films appear relatively dense after annealing to operational temperatures. We believe that the lack of detectable microporosity indicates that $\mathrm{Ba}$ transport will be confined to the grain boundaries in these films.

Porosity can be generated in these films with the inclusion of W. The electron micrograph of Figure 5 shows the result of annealing a $10 \mathrm{~nm}$ modulated W/BSCO/scandia film to $1300 \mathrm{~K}$. We find a series of microvoids of approximately $50 \mathrm{~nm}$ in cross-section distributed laterally through the film. The correlated position of the voids with the original layered structure indicate that they form as a result of $W$ diffusion and coalescence. X-ray diffraction (XRD) spectra, as shown in Figure 6 , generated at a $2^{\circ}$ incident angle during the annealing of this film confirm this interpretation. We find that no evidence for a $\mathrm{W}$ diffraction peak at $40.3^{\circ}$ below annealing temperatures of $1000 \mathrm{~K}$. This peak appears at low intensity at $1000 \mathrm{~K}$, continues to grow in intensity and narrows in width with annealing to $1300 \mathrm{~K}$. These results can be interpreted as a coalescence of the original $\mathrm{W}$ crystallites in the $10 \mathrm{~nm}$ layers into particles of a larger mean particle diameter. $\mathrm{W}$ is diffusing from adjacent regions of the original layer leaving behind microvoids in its absence. The presence of these voids offers $\mathrm{Ba}$ an alternate transport 

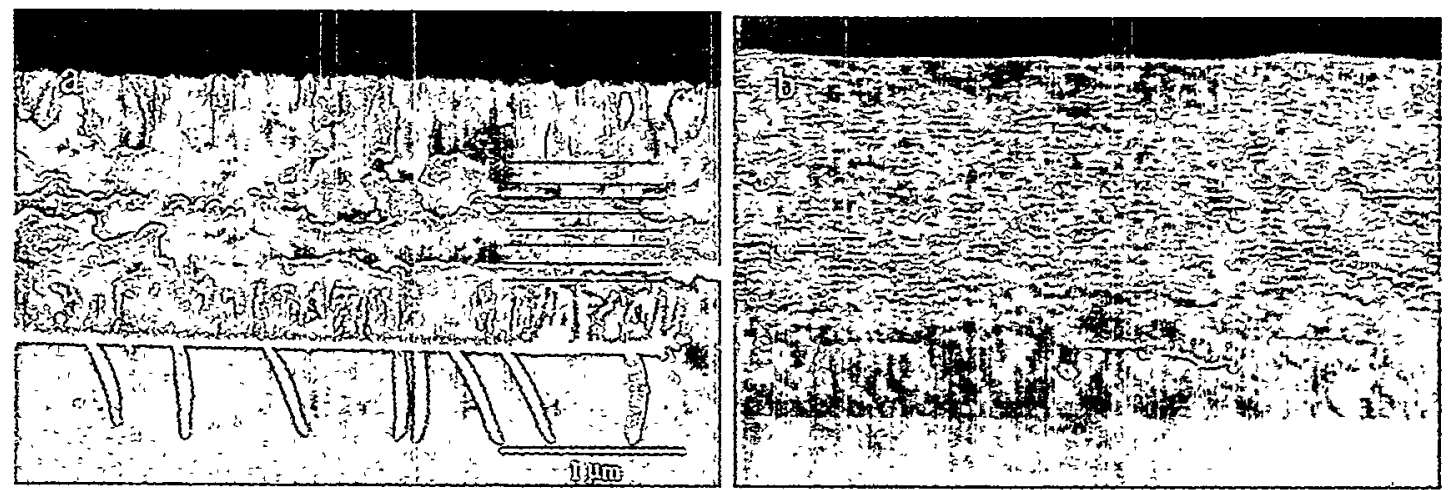

Figure 5: Cross sectional electron micrographic views of two composition modulated films annealed to $1300 \mathrm{~K}$ : a) $100 \mathrm{~nm} \mathrm{BSCO} / \mathrm{Sc}_{2} \mathrm{O}_{3}$ (lines are guides for probable location of interfaces) and b) $10 \mathrm{~nm}$ W/BSCO/ $\mathrm{Sc}_{2} \mathrm{O}_{3}$ (similar magnification as Figure 4a)

route to the surface, spending part of its time undergoing vapor phase transport across voids. The effective transport rate would be expected to be increased due to a decreased effective transport length. The possibility of tailoring the $\mathrm{W}$ layer thickness to facilitate connectivity in these pores would greatly increase $\mathrm{Ba}$ transport rates.

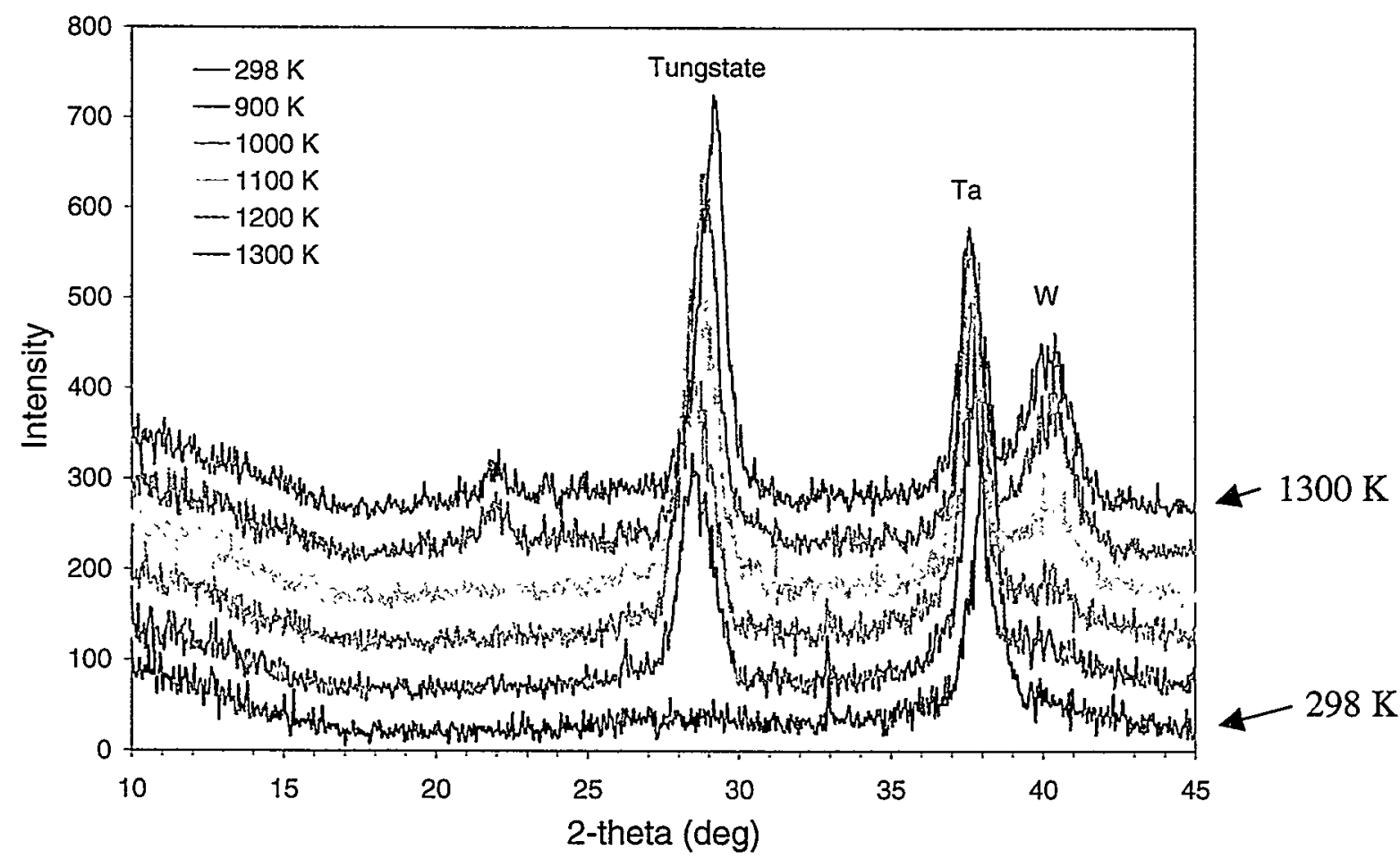

Figure 6: $2^{\circ}$ grazing incident angle XRD spectra for a modulated $10 \mathrm{~nm} \mathrm{~W} / \mathrm{BSCO} / \mathrm{Sc}_{2} \mathrm{O}_{3}$ film annealed at various temperatures 


\section{Film Chemistry}

The bulk film chemistry is monitored with annealing using XRD. The ability to generate coherent diffraction peaks is a function of the crystallite size at the investigated temperatures. We find that coherent data cannot be generated for initial films containing $10 \mathrm{~nm}$ layers but can for layers of $100 \mathrm{~nm}$. We gain no definitive information for $10 \mathrm{~nm}$ layer films with annealing to temperatures up to $1300 \mathrm{~K}$. We conclude that scandate and tantalate phase formation is highly dispersed and does not lead to large product crystallite sizes.

The fact that by-products are formed on annealing is demonstrated in the XRD data of Figure 6. A broad, intense peak appears at $28.5^{\circ}$ at $900 \mathrm{~K}$. The position is consistent with a $\mathrm{Ba}, \mathrm{Sr}$ or mixed $\mathrm{Ba}, \mathrm{Sr}$ tungstate phase. Further annealing narrows this peak and shifts it to slightly greater diffraction angles. The appearance of the tungstate phase clearly indicates $\mathrm{W}$ oxidation and suggests $\mathrm{Ba}$ reduction in the film. The changes in the tungstate peak lead and mirror the $\mathrm{W}$ coalescence indicating that the movement of $\mathrm{W}$ serves to promote $\mathrm{Ba}$ reduction.

Free $\mathrm{Ba}$ production appears to result from scandate and tantalate formation in the absence of $\mathrm{W}$. The data of Figure 7 show the results of annealing a BSCO/scandia bi-layer on a Ta electrode. Discrete features can be discerned because of the much thicker $(400 \mathrm{~nm})$ individual layers. The results show the impact of varying the grazing incident angle on the resulting diffraction spectra. Increasing the angle results in a larger sampling depth of

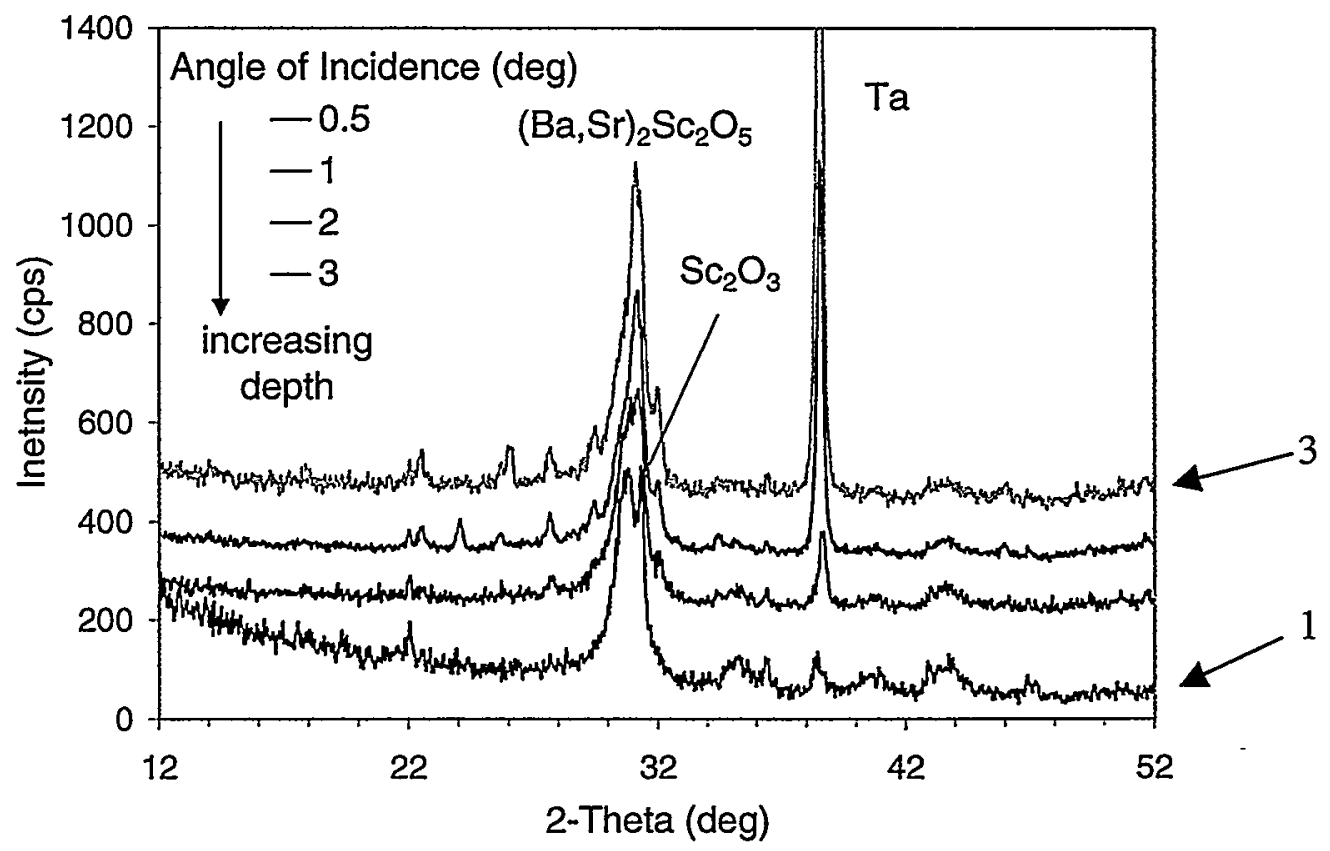

Figure 7: Grazing incidence variable angle XRD spectra of a $\mathrm{BSCO} / \mathrm{Sc}_{2} \mathrm{O}_{3}$ bi-layer film deposited on $\mathrm{Ta}$ and annealed to $1300 \mathrm{~K}$

the emitter film. We find the presence of peaks at $30.8^{\circ}$ and $31.6^{\circ}$ which are consistent with the formation of a $\mathrm{Ba}$ or $\mathrm{Sr}$ scandate phase $\left((\mathrm{Ba}, \mathrm{Sr}) \mathrm{Sc}_{2} \mathrm{O}_{5}\right)$ and the presence of scandia, respectively $[9,10]$. A shoulder is detected at $32^{\circ}$ indicative of a tantalate phase, 
possibly of composition. The tantalate occurs at the back of the film while the scandate is distributed throughout the bulk of the film. Kovba et al. have shown that $\mathrm{Ba}_{2} \mathrm{Sc}_{2} \mathrm{O}_{5}$ is the first eutectic compound that forms in the Ba-rich binary oxide[11].

\section{Film Surface Chemistry}

Film surface composition can be tracked during the annealing process using Auger electron spectroscopy (AES). Surface composition is tracked in the vacuum test chamber by translation of the sample to the focal point of a Physical Electronics 12-150 cylindrical mirror analyzer. A $3 \mathrm{keV}$ beam is used to stimulate Auger emission. Beam currents are kept to less than $1 \mu \mathrm{A} \cdot \mathrm{cm}^{-2}$ to minimize stimulated desorptive damage to the films. The pressure is maintained at nominally $1 \times 10^{-7} \mathrm{~Pa}$ during sample annealing and analysis via a combination of turbomolecular and $\mathrm{Ti}$ sublimation pumping.

Results show that layer intermixing near the surface occurs at low anneal temperatures for modulated films with $10 \mathrm{~nm}$ thick layers. Figure 8 shows a plot of the surface composition determined by $\mathrm{AES}$ as a function of anneal temperature for a scandia terminated film. The data was acquired with a $3 \mathrm{keV}$ electron beam at sample current densities of less than $1 \mu \mathrm{A} \cdot \mathrm{cm}^{-2}$. The unannealed surface shows the presence of Sc (Sc LMM transition at $327 \mathrm{eV}$ ) and $\mathrm{O}(\mathrm{O} \mathrm{KLL}$ transition at $502 \mathrm{eV}$ ) consistent with its termination. The $\mathrm{Ba}$ MNN transition at $583 \mathrm{eV}$ is also visible despite an estimated sampling depth of $4.5 \mathrm{~nm}$, based on the scattering model of Tanuma et al.[10]. We

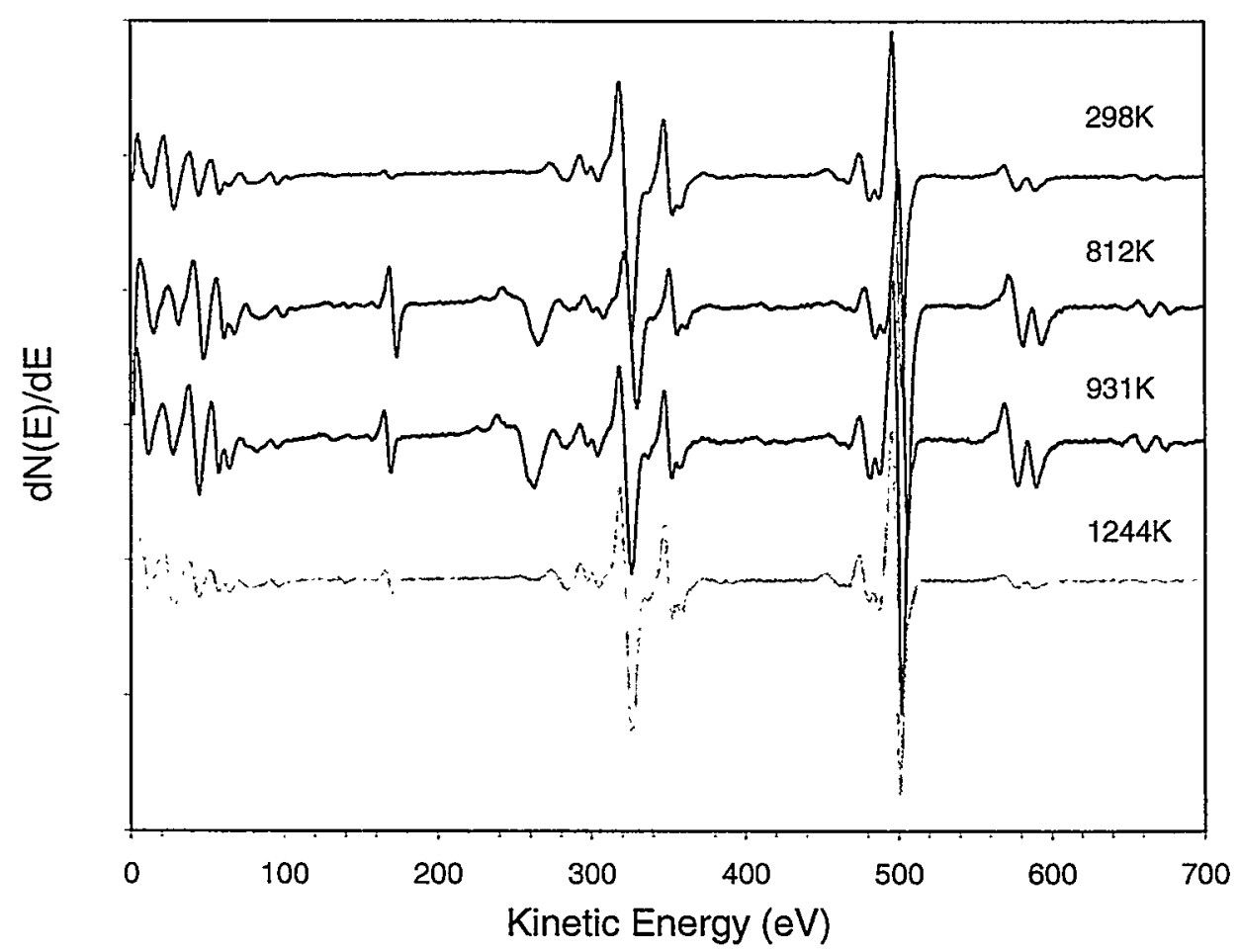

Figure 8: Variation in surface composition with annealing temperature as detected using Auger electron spectroscopy. Anneal times are typically one hour. 
interpret this result to indicate that some degree of layer intermixing occurs during the $573 \mathrm{~K}$ deposition process. Annealing the film to temperatures as low as $812 \mathrm{~K}$ produces a $\mathrm{Ba}$ near surface concentration of 6.0 at.\%. Further annealing to $931 \mathrm{~K}$ produces only minor changes in relative concentrations of surface species, indicating that a saturation $\mathrm{Ba}$ coverage is achieved at relatively low temperatures. We find that contaminant atomic $\mathrm{Cl}$ (LMM at $173 \mathrm{eV}$ ) and $\mathrm{C}$ (KLL at $266 \mathrm{eV}, \mathrm{CO}$ and $\mathrm{CO}_{2}$ as a source) adsorb as the surface becomes populated with $\mathrm{Ba}$. Attention must be paid to chamber cleaning to ensure that the effects of positive dipole formation at the surface with $\mathrm{Ba}$ are not offset by the adsorption of electronegative contaminants. The surface concentration of $\mathrm{Ba}$ is significantly reduced with annealing temperatures approaching $1300 \mathrm{~K}$. We presume that at such temperatures the Ba desorption rate exceeds the bulk transport and generation rates and surface depletion occurs.

We obtain a better idea of the balance achieved in the Ba surface concentration by constantly monitoring this value at temperature with a candidate film. The results of this type of experiment are shown for a BSCO/scandia modulated film containing $2 \mathrm{~nm}$ thick individual layers. Figure 9 shows the variation in surface concentration as a function of anneal temperature for this scandia terminated film. A saturated Ba surface concentration of approximately 20 at.\% is produced at $875 \mathrm{~K}$. This value is maintained for temperatures up to approximately $1100 \mathrm{~K}$, followed by a gradual decay with increased temperature. This data establishes an estimate of the window of stability in electron emission expected for these films. We find an approximate correlation between this temperature range and the range over which stable emission properties are observed.

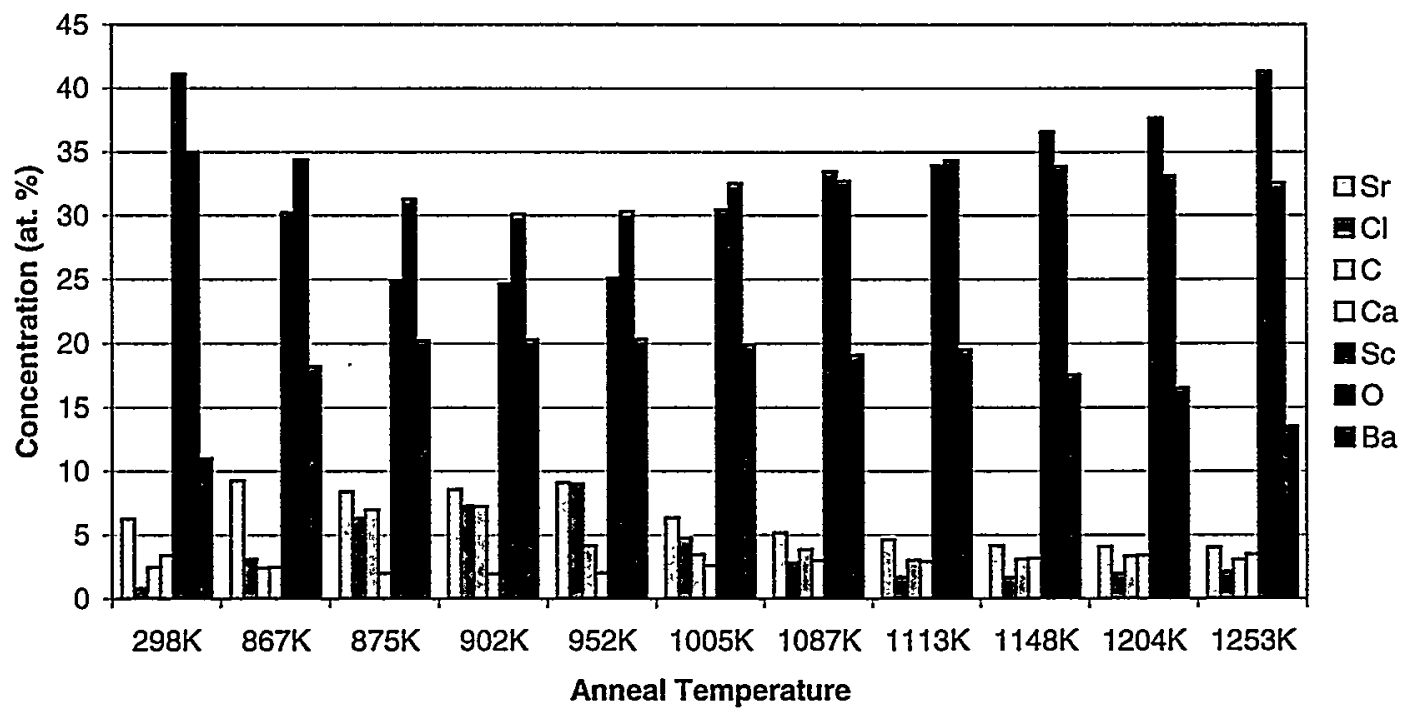

Figure 9: AES derived surface concentrations for a $10 \mathrm{~nm}$ modulated $\mathrm{BSCO} / \mathrm{Sc}_{2} \mathrm{O}_{3}$ film at various anneal temperatures. Typical anneal times are one hour.

\section{Emission Properties of Thin Film Emitters}

Thermionic emission current density from a single surface, in the absence of space charge, is given by the Richardson-Dushman equation: 


$$
J_{0}=A T_{E}^{2} \exp \left(\frac{-e \phi_{E}}{k T_{E}}\right)
$$

where the emission constant, $A$, has a theoretical value of $120 \mathrm{~A} \cdot \mathrm{cm}^{-2} \cdot \mathrm{K}^{-2}, T_{E}$ is the emitter temperature, $\mathrm{k}$ is the Boltzman constant, and $\phi_{\mathrm{E}}$ is the emitter work function. The application of a high field $\left(E_{a}\right)$ between the emitting surface and a collector produces a Schottky effect at the emitter surface. In this range of saturation, the current density can be expressed as:

$$
J=J_{0} \exp \left[\frac{e}{k T}\left(\frac{e E_{a}}{4 \pi \varepsilon_{0}}\right)^{1 / 2}\right]
$$

where $\varepsilon_{0}$ is the vacuum permittivity. The Schottky formula can be used to evaluate the nature of electron emission from a cathode. The extent to which $J$ is correlated with $E_{a}{ }^{1 / 2}$ at low fields is a measure of the magnitude of space charge and work function uniformity. Saturation current densities should occur as soon as the applied field is equivalent to the difference in emitter and collector work functions. Current versus field curves can be used to extrapolate zero field current densities that represent emission conditions when the cathode properties are the dominant parameters. The zero field current density is measured over a range of temperatures, used as an input to the Richardson-Dushman equation, and yields the cathode work function and an apparent emission coefficient $\left(A^{*}\right)$. A* generally differs from the theoretical A value because of a non-unity electron transmission coefficient at most surfaces and because of non-uniform emission at some surfaces.

Emission testing is conducted in an ultrahigh vacuum system maintained at a base pressure of less than $1 \times 10^{-7} \mathrm{~Pa}$. The emitter die is attached to an aluminum nitride plate using an Aremco 569 alumina-based ceramic. The nitride plate is resistively heated by passing current through a $600 \mathrm{~nm}$ Ta film deposited on one side. Palladium wire is bonded to the electrode structure to establish an electrical connection to the cathode. This die/plate assembly is mounted on a manipulator that can be translated to varies positions within the vacuum chamber. A molybdenum electrode, of equivalent dimensions to the cathode, serves as a collector for emission tests. This collector is mounted on a second manipulator providing for an adjustable inter-electrode gap down to $10 \mu \mathrm{m}$ in dimension. A Keithley 238 unit is used for electrode potential control and current measurement. Emission is generally evaluated at 100 to $150 \mu \mathrm{m}$ gap spacings.

Low temperature electron emission is achieved with these modulated films. Figure 10 shows the temperature and applied field dependence on the current density of a particular film. This film was comprised of four modulated layers of $\mathrm{BSCO}$ and $\mathrm{Sc}_{2} \mathrm{O}_{3}$ of $200 \mathrm{~nm}$ in

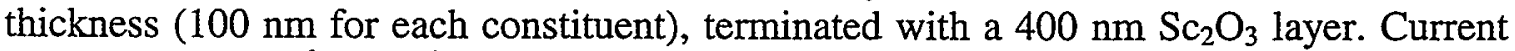
densities of $2 \times 10^{-6} \mathrm{~A} \cdot \mathrm{cm}^{-2}$ are measured at $875 \mathrm{~K}$ at $7 \mathrm{kV} \cdot \mathrm{cm}^{-1}$ using a $150 \mu \mathrm{m}$ gap and a molybdenum collector. The initial annealing of this film was conducted at $875 \mathrm{~K}$, indicating that stable emission can be achieved at low temperatures. Typical annealing times are found to be several hours prior to the onset of stable emission currents. The temperature and time values are consistent with conditions required to achieve $\mathrm{Ba}$ saturation levels at the film surface. 


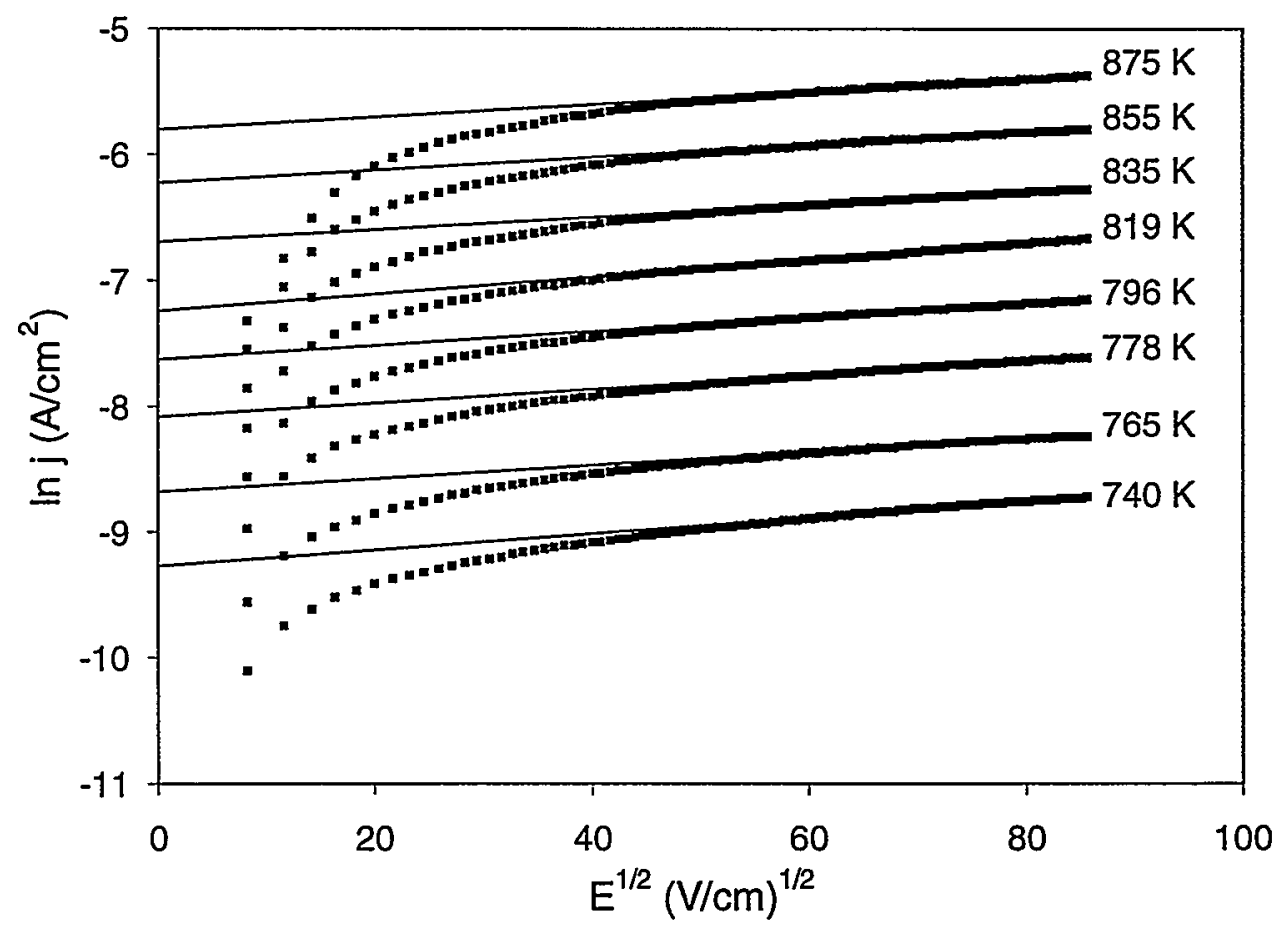

Figure 10: Schottky analysis of a modulated $\mathrm{BSCO} / \mathrm{Sc}_{2} \mathrm{O}_{3}$ film with $100 \mathrm{~nm}$ individual layers and $\mathrm{Sc}_{2} \mathrm{O}_{3}$ termination.

These films possess a high field work function of nominally $1.2 \mathrm{eV}$. The variation in emission current density as a function of both applied field and temperature is shown in Figure 10. The fact that a high degree of linearity is observed at fields above $1.6 \mathrm{kV} \cdot \mathrm{cm}^{-1}$ indicates that a true saturation current density is achieved. Attempts to correct the current density for space charge effects for this series and higher temperature data produce no significant changes in the shape of these curves [11]. This result demonstrates that space charge is not a current limiting factor under our experimental conditions. Zero field current density values are extrapolated from this data and serve as an input to the Richardson-Dushman equation. Figure 11 shows a plot of these zero field current density values versus temperature in the form of the Richardson-Dushman equation. A linear dependence is found for these values relative to the inverse of the temperature, where the slope and current density intercept are related to the high field work function and the apparent emission coefficient, respectively. Additional data is included in Figure 11 to investigate the effect of annealing and subsequent operation at higher temperatures. The results of linear regression fits to these data sets are given in Table 1 . We find a nominal value of $1.2 \mathrm{eV}$ for a range of activation/operation temperatures from 875 to $1004 \mathrm{~K}$. This value of work function represents a minimum relative to the model system experimental work of Zagwijn et al. [12] and the theoretical work of Müller [13]. The work function ranges from 1.18 to $1.26 \mathrm{eV}$ with no apparent trend with increased operational temperatures. The emission coefficients range from 68 to $16 \mathrm{~mA} \cdot \mathrm{cm}^{-2} \cdot \mathrm{K}^{-2}$ and show a decrease by a factor of approximately 3 over the investigated temperature range. These 
values are a factor of $10^{-3}$ to $10^{-4}$ lower than the theoretical value of $120 \mathrm{~A} \cdot \mathrm{cm}^{-2} \cdot \mathrm{K}^{-2}$ and considerably lower than a practical limit of $7 \mathrm{~A} \cdot \mathrm{cm}^{-2} \cdot \mathrm{K}^{-2}$ found for state-of-the-art metal coated dispenser cathodes[14]. This large discrepancy appears to be the result of underutilization of the available emitting surface area.

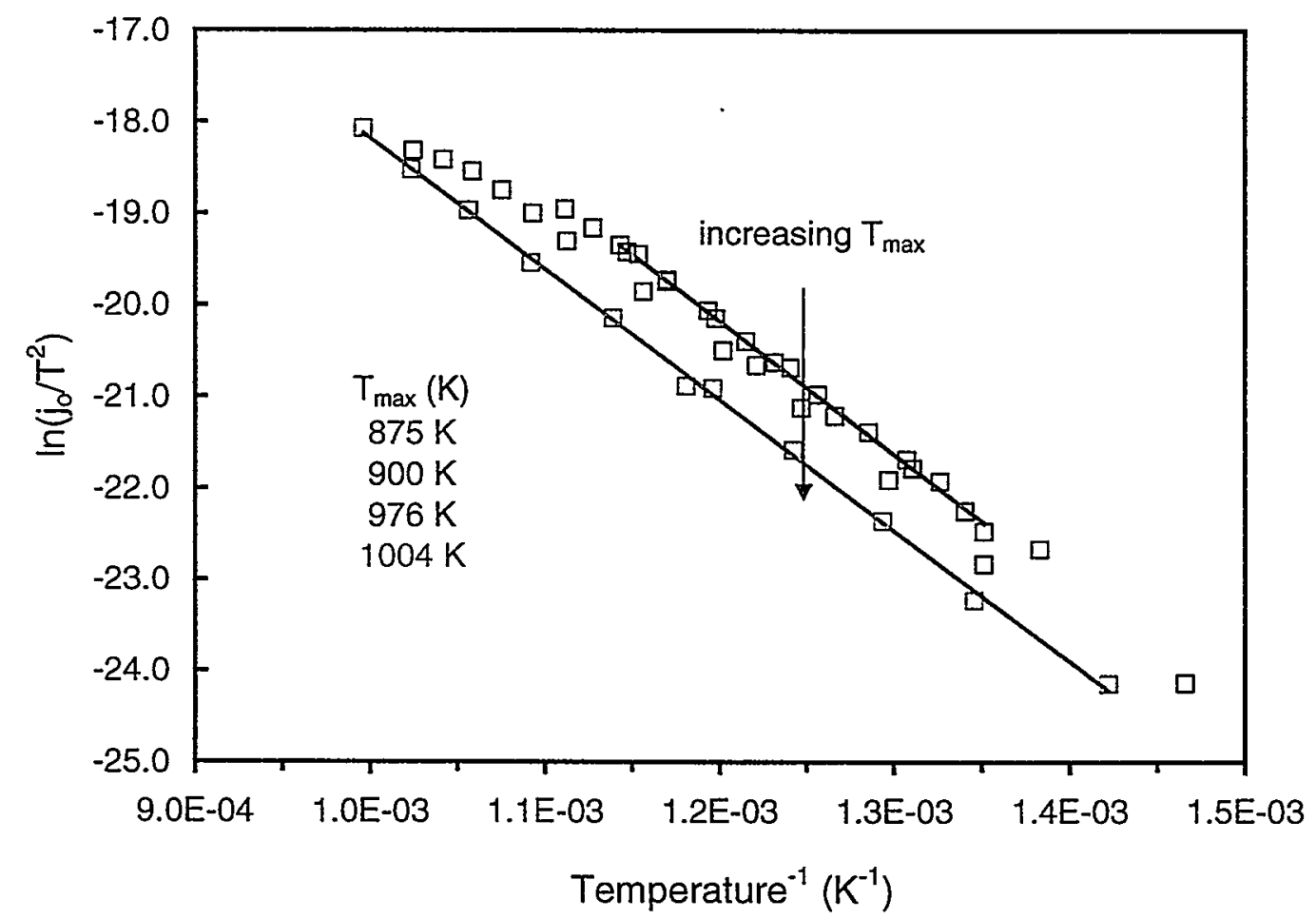

Figure 11: Richardson-Dushman plots for a $100 \mathrm{~nm}$ modulated $\mathrm{BSCO} / \mathrm{Sc}_{2} \mathrm{O}_{3}$ film after annealing to an increasing maximum temperature

Table1: Variation in Emission Properties with Maximum Annealing Temperature

\begin{tabular}{|c|c|c|}
\multicolumn{1}{c}{$\mathrm{T}_{\max }(\mathrm{K})$} & $\phi(\mathrm{eV})$ & $\mathrm{A} *\left(\mathrm{~mA} \cdot \mathrm{cm}^{-2} \cdot \mathrm{K}^{-2}\right)$ \\
\hline 875 & 1.26 & 68 \\
\hline 900 & 1.24 & 52 \\
\hline 976 & 1.18 & 16 \\
\hline 1004 & 1.24 & 22 \\
\hline
\end{tabular}

Under utilized emission area appears to be the result of patch effects on these films. The data of Figure 10 show a deviation from linearity for fields below approximately 1.6 $\mathrm{kV} \cdot \mathrm{cm}^{-1}$. Because evidence for space charge does not exist under these conditions, we conclude that this nonlinearity is due to heterogeneity in the local work function distribution at the surface. Low work function patches would result in a restriction of emission at low field values because of field gradients generated at the patch boundary [15]. Using the approximations of Herring and Nichols, we relate the field where 
deviation occurs to the mean diameter of a low work function patch [16]. Assuming $100 \%$ electron transmission at our surfaces, the ratio of emission coefficient with the theoretical value will represent the fraction of the surface actually emitting electrons. Following this approach, we estimate that patches to be several tens of microns in diameter and at densities of several hundred per square centimeter.

The existence of patches indicates a non-uniform coverage of free $\mathrm{Ba}$ at the surface. Possible limits to this value include a low rate of free $\mathrm{Ba}$ production within the film, limited transport of $\mathrm{Ba}$ through the film, and a low surface diffusion rate relative to the desorption rate. Free $\mathrm{Ba}$ production within the film does not appear to be a primary limitation. Emission measurements have been made for similar films deposited on cathode nickel substrates. This substrate is a nickel alloy which contains $3.7 \mathrm{wt} . \% \mathrm{~W}$ and $0.08 \mathrm{wt} . \% \mathrm{Fe}, \mathrm{Mg}$ and Si. These elemental additives are believed to be responsible for the reduction of $\mathrm{Ba}$. These films were tested in a pulsed field condition in an electron gun configuration up to a temperature range of $1110 \mathrm{~K}$ [17]. A Schottky plot is shown in Figure 12 for data generated at $1110 \mathrm{~K}$. Emission current densities of 40 to $240 \mathrm{~mA} \cdot \mathrm{cm}^{-2}$ were measured for fields of 1.6 to $56 \mathrm{kV} \cdot \mathrm{cm}^{-1}$. These saturation current density values match for a film with a work function of $1.2 \mathrm{eV}$ and an emission coefficient of $70 \mathrm{~A} \cdot \mathrm{cm}^{-}$ ${ }^{2} \cdot \mathrm{K}^{-2}$ at equivalent temperature and field values. We conclude that the presence of a known activating material at the back of the film is not sufficient for eliminating emission heterogeneity. This conclusion points to either a limiting $\mathrm{Ba}$ transport rate in the film or a

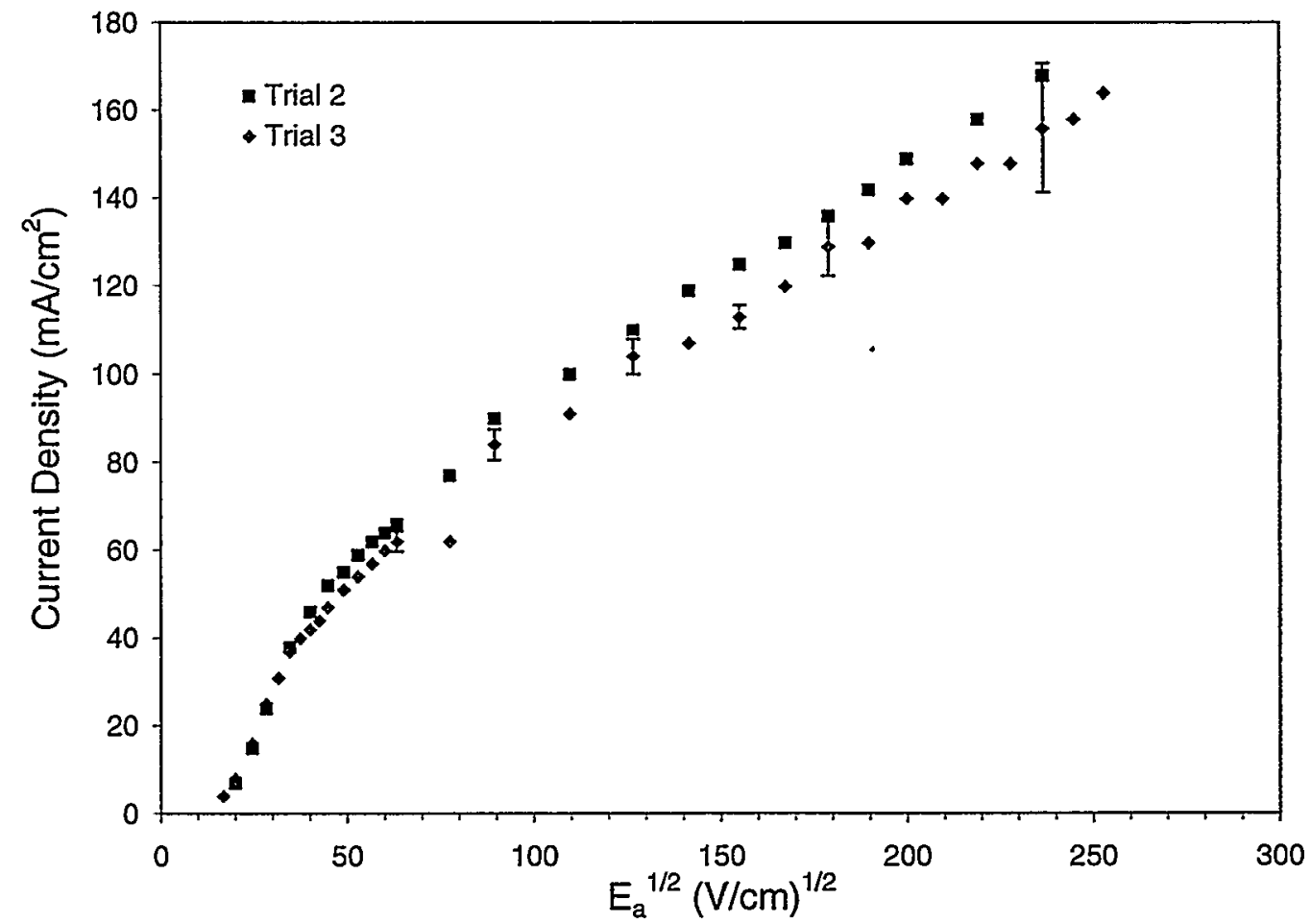

Figure 12: Schottky curves acquired at $1110 \mathrm{~K}$ for a BSCO/Sc2O3 modulated film deposited on a cathode $\mathrm{Ni}$ (alloy 129). 
limited mobility at the oxide surface. The inclusion of porosity in these films and the use of metal capping layers are two tests proposed in an attempt to identify the source of poor surface utilization. Films possessing porosity generated by metal interlayer coalescence have not been tested to date.

\section{Conclusions}

We demonstrate an ability to deposit thin film thermionic emitters with process techniques that can be integrated into standard integrated circuit fabrication. These films are mixed oxides containing $\mathrm{Ba}$ and are deposited using standard rf sputtering. We show that these films can be produced with a practical minimum work function of $1.2 \mathrm{eV}$. We find that only a small fraction of the surface actually possesses this low work function. The existence of a variation in work function across the surface leads to much smaller than anticipated emission current densities and renders these films as impractical sources for low field energy conversion applications. The most likely explanation for the underutilization of the surface is either a limited bulk transport rate of free $\mathrm{Ba}$ or limited surface mobility of the Ba. Increased film porosity and metal capping layers are two strategies that should minimize these effects and represent simple modifications to the current fabrication process. We demonstrate a novel method for generating porosity in these films using metal interlayer coalescence.

\section{Acknowledgements}

Albert C. Marshall and Francis J. Wyant (Sandia National Laboratories) provided valuable input for this work. We thank Glenn P Scheitrum and George Caryotakis (Stanford Linear Accelerator) for the use of their laboratory and discussion of ideas. Discussions with Ulrich Schiebel, Georg Gärtner and P. Geittner (Phillips Research) are gratefully acknowledged. Michael J. Russell (Sandia National Laboratories) provided technical assistance.

\section{References}

1. D.B. King J.R. Luke, F.J. Wyant, "Results form the Microminiature Thermionic Converter Testing Program," Proc. Space Technology and Applications International Forum, M.S. El-Genk, ed., American Institute of Physics, New York, 1999, Vol. 458, 1432-1437.

2. R.E. Thomas, J.W. Gibson, G.A. Haas and R.H. Abrams, IEEE Trans. Electron Dev. 37(3), 1990, 201-208.

3. A.H. Beck, "High Current Density Thermionic Emitters: A Survey," Proc. I.E.E., 106(B), 1958, 372-388.

4. K.R. Zavadil, J.A. Ruffner and D.B. King, "Fabrication of Thin Film Dispersed Tungsten and Alkaline Earth Oxide Thermionic Cathodes using RF Sputtering for Microminiature Energy Conversion/Recovery Applications," Patent Application, SD6354/S-92,327, 1999.

5. M. Saito, R. Suzuki, K. Fukuyama, K. Watanabe, K. Sano and H. Nakanishi, IEEE Trans. Electron Dev. 36(1), 1990, 201-208.

6. K.R. Zavadil, J.A. Ruffner, D.B. King, "Characterization of Sputter Deposited Thin Film Scandate Cathodes for Miniaturized Thermionic Converter Applications," Proc. 
Space Technology and Applications International Forum, M.S. El-Genk, ed., American Institute of Physics, New York, 1999, Vol. 458, 1438-1443.

7. J.R. Carter and R.S. Feigelson, J. Amer. Ceram. Soc., 47(3), 1964, 141-144.L.M.

8. W. Kwestroo, C. Langereis and H. Nabben, Mat. Res. Bull., 17, 1982, 641-646.

9. Kovba, L.N. Lykova, M.V. Paromova and T.A. Kalinina, Dokl. Chem. USSR, 260(4), 1981, 898-900.

10. S. Tanuma, C.J. Powell and D.R. Penn, Surf. Interfac. Anal., 20, 1993, 77-89.

11. J. Hasker and P.A.M. Van Dorst, IEEE Trans. Electron Dev. 36(1), 201-208 (1989).

12. P.M. Zagwijn, J.W.M. Freken, U. van Slooten and P.A. Duine, Appl. Surf. Sci., 111, 1997, 35-41.

13. W. Müller, Appl. Surf. Sci., 111, 1997, 30-34.

14. G. Gärtner, P. Geittner, H. Lydtin and A. Ritz, Appl. Surf. Sci., 111, 1997, 11-17.

15. L.K. Hansen, J. Appl. Phys., 37(12), 1966, 4498-4502.

16. C. Herring and M.H. Nichols, Rev. Mod. Phys., 21(2), 1942, 185-270.

17. R.J. Umstattd, "Plasma deposition of Oxide Coated Cathodes," $\mathrm{PhD}$ Dissertation, University of California - Davis, 1998. 


\section{Distribution:}

\section{Unlimited Distribution:}

1 MS9018 Central Technical Files, 8940-2

2 MS0899 Technical Library, 4916

1 MS0612 Review \& Approval Desk, 4912, For DOE/OSTI

1 MS0161 Patent \& Licensing, 11500

1 MS0188 LDRD Program Office, 4001

1 MS1435 A. Kathleen Hays, 1800

1 MS0340 Wendy R. Cieslak, 1832

$5 \quad$ MS0340 Kevin R. Zavadil, 1832

1 MS1349 William F. Hammetter, 1846

3 MS1349 Judith A. Ruffner, 1846

1 MS0736 Thomas Blejwas, 6400

1 MS0744 Dennis L. Berry, 6403

3 MS0744 Donald B. King, 6403 